\title{
Childhood Predictors of Desistance and Level of Persistence in Offending in Early Onset Offenders
}

\author{
L. van Domburgh • R. Loeber • D. Bezemer • \\ R. Stallings $•$ M. Stouthamer-Loeber
}

Published online: 10 June 2009

(C) The Author(s) 2009. This article is published with open access at Springerlink.com

\begin{abstract}
Childhood predictors of adolescent offending careers were studied in 310 boys from the longitudinal Pittsburgh Youth Study who started offending prior to age 12. Three main groups were distinguished: serious persisters $(n=95)$, moderately serious persisters $(n=117)$, desisters $(n=$ $63)$, and an intermittent group $(n=35)$. Group membership was predicted using risk and promotive factors measured in childhood. Serious and moderately serious persisters could be distinguished well from desisters $(29.2 \%$ and $32.3 \%$ explained variance). Distinction between the two persister groups proved somewhat more difficult $(20.9 \%$ explained variance). More serious persisters than desisters showed disruptive behavior, while moderately serious persisters fell in between. Further, more moderately serious persisters were marked by social disadvantage. Family involvement, small family and positive peer relationships were promotive of
\end{abstract}

L. van Domburgh

Department of Child and Adolescent Psychiatry,

VU University Medical Center,

Amsterdam, The Netherlands

R. Loeber $\cdot$ R. Stallings $\cdot$ M. Stouthamer-Loeber

Department of Psychiatry, University of Pittsburgh,

Pittsburgh, PA, USA

R. Loeber

Department of Developmental Psychology,

VU University Medical Center,

Amsterdam, The Netherlands

D. Bezemer

Department of Bio-Statistics, VU University Medical Center,

Amsterdam, The Netherlands

L. van Domburgh $(\bowtie)$

VUMC Medical Center,

c/o De Bascule, PO Box 303,

1115 ZG Duivendrecht, The Netherlands

e-mail: 1.vandomburgh@debascule.com desistance. Concluding, early onset offenders show considerable heterogeneity in their adolescent offending careers which seem to some extent to be predicted by different sets of risk and promotive factors.

Keywords Desistance - Adolescent persistence ·

Early onset delinquency - Childhood onset delinquency . Childhood onset offending - Early desistance .

Seriousness of persistence

Although childhood onset offenders, i.e. those with an age of onset below age twelve, are at high risk of becoming serious persistent offenders (e.g. Kazemian and Farrington 2005; Loeber and Farrington 2001), studies show considerable heterogeneity regarding both duration and seriousness of subsequent adolescent offending careers (Stouthamer-Loeber et al. 2008; Chung et al. 2002). Identification of childhood onset offenders most at risk of continued offending and the factors predictive of such persistence is crucial in reducing offending behavior (Loeber and LeBlanc 1990).

So far, the focus of persistence studies has been on the prediction of serious forms of delinquency or delinquency in general, while moderately serious delinquency has not been studied as a separate category. However, several studies have demonstrated that moderate forms of delinquency are part of a developmental pathway starting with minor delinquency followed by moderately serious delinquency and eventually escalating in serious delinquency (e.g. Loeber et al. 1993; Loeber and Farrington 2001). Therefore, studying moderately serious delinquency is important, first, because it can be a stepping stone to serious delinquency. Second, moderately serious in contrast to serious delinquency has a higher base rate making prediction more feasible. Third, only a minority of the moderately serious delinquent boys advance to the serious level. The moderately serious offenders who do not escalate into serious offending may still persist in (frequent) 
moderately serious offending, and thereby constitute a riskgroup. Therefore, identification of factors predictive of persistent moderately serious offending may refine our risk taxation and provide us with tools to better tailor interventions to prevent boys' escalation in serious offending. Further, the identification of factors predictive of cessation of offending behavior during a period in which delinquency is at its peak may also provide essential knowledge for the reduction of offending behavior (Loeber and Le Blanc 1990). Therefore, this study aims at identifying childhood characteristics that distinguish between serious persistent, moderately serious persistent and early desisting adolescent offending careers in a sample of childhood onset offenders.

\section{Theories of Early Onset Adolescent Offending Careers}

Notwithstanding the considerable debate about the causal mechanisms, most causal theories on early onset persistent offending hypothesize that the interaction between individual characteristics of the child and his or her social environment, especially parenting practices, is crucial in the development of early onset persistent offending (e.g. Moffitt 1993; Patterson 1996; Thornberry and Krohn 2001). One group of theories distinguishes between two etiologically different subgroups of offenders, namely early-onset life-course-persistent (LCP) offenders and adolescent-limited (AL) offenders (Moffitt 1993; Patterson 1996). In the explanation of LCP offending, Moffitt (1993) focused particularly on 'biologically based' individual neuropsychological deficits made apparent by cognitive deficits, difficult temperament and hyperactivity as the key feature of this group (Moffitt 1993; Raine et al. 2002), while, Patterson (1996) focused on the coercive interaction patterns between children who display problematic behavior and parents with poor parental practices.

A second group of theories hypothesizes that causal mechanisms are similar regardless of age of onset (Gottfredson and Hirschi 1990; Akers 1998; Sampson and Laub 2005; Thornberry and Krohn 2001). According to these theories the higher risk of persistence of early onset offenders is caused by higher rates of risk factors and longer exposure to these factors. According to control theory (Gottfredson and Hirschi 1990), low self control established by age eight and apparent by sensation seeking, psychopathic features and substance use, is the key causal factor to persistent and serious delinquency. In contrast, social learning theory states that persistence is guided by perceived costs and rewards (Akers 1998), which is determined by individual factors such as attitudes towards delinquent behavior, previous experiences, and social factors such as provisions of reward and punishment by family and peers. Finally, social control theory states that adolescent persistence is correlated with negative and weak social bonds, low academic achievement, and low school commitment (Hirschi 1969). In addition, Thornberry and Krohn (2001) postulated that the interaction between individual impairment and social disadvantage increases the likelihood of these mechanisms and is thereby predictive of both onset and persistence of offending.

Few theories focus specifically on desistance. Those that address the issue mainly focus on desistance in late adolescence and early adulthood as crime levels tend to decrease (Stouthamer-Loeber et al. 2008; Laub and Sampson 2001). In their review of the literature, Laub and Sampson (2001) summarized several plausible explanations of desistance. A first body of explanations views late adolescent and adult desistance as naturally occurring phenomena due to aging or maturation (e.g. Glueck and Glueck 1943; Gottfredson and Hirschi 1990; Moffitt 1993) and thereby do not consider desistance in early adolescence. Second, the life course perspective of social control theory (Sampson and Laub 1993; Thornberry and Krohn 2001) focuses on variations in informal social control or social bonds proximal to desistance as main causes of desistance. Further, Thornberry (2005) stated that on rare occasions, early adolescent desistance may also be caused by already available pro-social potential inhibiting the further development of an offending career. Third, rational choice theory of desistance stresses the choices individuals make to desist (Paternoster 1989), which requires some level of maturation, and is therefore less likely to occur at a young age. Finally, social learning theory hypothesizes that the basic variables that explain initiation also in a reverse manner account for desistance (e.g., Akers 1998).

In summary, on the one hand, some theories stress that individual stable risk factors for persistence develop early in life from the interaction between individual and environmental factors and stress that desistance in early onset offenders is rare (Moffitt 1993; Gottfredson and Hirschi 1990). On the other hand, some theories focus on developmental changes and as such stress the importance of proximal social bonds and academic achievement for persistence and desistance (Laub and Sampson 2001; Thornberry 2005). None of these theories focus on the persistence of less serious forms of delinquency as they either concentrate on serious offending or delinquency in general. However, according to the more dimensional theories it can be expected that moderately serious persisters in contrast to serious persisters in offending display intermediate levels of risk factors. None of the theories focused on the explanation of desistance in offending at an early age.

\section{Studies on Early Onset Adolescent Offending Careers}

Studies on the value of childhood measures when predicting early onset adolescent persistence versus desistance have been inconclusive (Fergusson et al. 1996; Chung et al. 2002; Cottle et al. 2001; Aguilar et al. 2000; Moffitt et al. 2002; Raine 
et al. 2005; Stouthamer-Loeber et al. 2008; Farrington and Hawkins 1991). Some studies reported that similar childhood individual and environmental risk factors operate in adolescent desisters and persisters, with desisters having risk profiles intermediate between persisters and non-offenders (Fergusson et al. 1996; Chung et al. 2002; Cottle et al. 2001). In contrast, other studies reported desisters to show as much individual risk factors as persisters in childhood (Aguilar et al. 2000; Moffitt et al. 2002; Raine et al. 2005), in addition to higher levels of internalizing difficulties such as depression, anxiety, and withdrawal, and higher levels of cognitive functioning (Moffitt et al. 2002; Raine et al. 2005). However, still others reported internalizing difficulties to be related to persistence instead of desistance in offending (Cottle et al. 2001; Stouthamer-Loeber et al. 2008). In contrast to individual characteristics, poor parenting practices, familial difficulties and social disadvantage have been consequently related to persistence, while low parental stress, good supervision and good housing quality have been related to desistance in delinquency (Stouthamer-Loeber et al. 2008; Cottle et al. 2001; Farrington and Hawkins 1991). However Loeber and Wikström et al. (2000) found only no direct impact of neighborhood disadvantage on early onset serious offending. These results are also found when taking into account a broader context of antisocial behavior (Nagin and Tremblay 2001, 1999; Granic and Patterson 2006; Patterson et al. 1998; Aguilar et al. 2000; Fergusson and Horwood 2002). Finally, although peer interaction is a key feature in several theories it has not been studied extensively in early onset offenders. A limited number of studies have found childhood antisocial peer affiliation and gang membership to be related to adolescent delinquency (Lacourse et al. 2003; Stouthamer-Loeber et al. 2008). In summary, results on the predictive value of individual difficulties have been inconclusive, while parenting practices, social background, and peer affiliation seem to differentiate between early adolescent desistance and persistence.

Several studies on juvenile delinquency have shown a dose response relationship between the severity of offending and risk and promotive factors, indicating that the more serious the offending, the higher the number of risk factors and the lower the number of promotive factors (e.g. Stouthamer-Loeber et al. 2004). Along that line, more of the early onset serious persistent offenders as compared to the moderately serious persistent offenders are expected to be exposed to risk factors and fewer to promotive factors. Further, a limited number of studies have focussed on the identification of childhood predictors of adolescent offence severity (Miller-Johnson et al. 1999; Nagin and Tremblay 1999; Lee and Hinshaw 2004). However, results are contradictory and the studies often were limited to a few potential predictors. Some researchers have reported that childhood aggression and peer problems predict severity of offending in adolescence (Miller-
Johnson et al. 1999; Nagin and Tremblay 1999) while others did not find such a relationship (Lee and Hinshaw 2004).

The studies described above have several limitations. First, although several studies have focused on early onset reoffending, only a few studies have focused on desistance in early adolescence while none have distinguished between different severity levels of adolescent persistence. Second, most identified predictors have been risk factors, defined as factors that increase the probability of later delinquency, rather than promotive factors associated with a decreased probability of later delinquency (but see Pollard 1999; Lösel and Bender 2003). However, various studies have shown that both persistence and desistance are best predicted by a combination of risk and promotive factors (Stouthamer-Loeber et al. 1993, 2002, 2004; Loeber et al. 2008). Third, most studies used either self reports or court records. However, self-report can underestimate serious offenses such as rape and homicide, while official records have the disadvantage that they underestimate the prevalence of offending in general.

This paper addresses two questions. First, what is the prevalence of serious persistent offending, moderately serious persistent offending and desistance in a sample of childhood onset offenders? To counter the measurement weaknesses of earlier studies, a combined measure of both self-reported delinquency and court records will be used. Early onset will be defined as any moderate to serious offending prior to age twelve, while a distinction will be made between adolescent serious persistence, moderately serious persistence, and desistance. Thus, this study further refines earlier findings by Stouthamer-Loeber et al. (2008), who studied serious and moderately serious adolescent persisters as one combined group. The second question will be: which characteristics measured in middle childhood, that were found highly predictive of persistence in the general population (Loeber et al. 2008) and/or desistance in the combined moderate to serious offender group as studied by Stouthamer-Loeber et al. (2008), prospectively discriminate between early onset serious persistent, moderately serious persistent, and desistant adolescent offending careers?

\section{Method}

Participants

The participants of this study were inner-city adolescent boys from the youngest cohort of the Pittsburgh Youth Study, an ongoing longitudinal study that began in 1987. The sample of boys was randomly drawn from the first-grade of public schools; $85 \%$ of the boys and their caretakers (93\% of whom were biological mothers) consented to participate in a screening assessment. The top $30 \%$ of boys with the highest rates of antisocial behavior were selected, along with an equal 
number of boys randomly selected from the remaining $70 \%$. Every 6 months for the first six follow-up assessments and yearly thereafter, information on the child was gathered using self report, parent report, and teacher report. Full details of participant characteristics and data collection have been published previously (Loeber et al. 2008, 1998). The present investigation focused on those boys who have shown antisocial behavior before the age of twelve as reported by child, parent and/or teacher $(N=333)$. At the last data phase used, the participation rate was $89 \%$, reflecting a low attrition rate. Due to missing data in several assessments, 23 children were not included in the analyses.

For this study, data from the assessments were combined to reflect behaviors occurring in five periods starting at first grade. Because not all children in first grade are of the same age, there was some overlap in age between the time periods. The mean ages at the first and last assessment of each time period were as follows: middle childhood ( 7.43 years ( $\mathrm{sd} 0.56)$ - 8.96 years (sd 0.56)), late childhood (9.46 years (sd 0.56)-10.94 years (sd 0.56)), early adolescence (11.99 years (sd 0.56) 13.99 years (sd 0.56)), middle adolescence $(15.05$ years $(\mathrm{sd}$ $0.57)-16.97$ years (sd 0.57)), and late adolescence (17.92 years (sd 0.61) - 20.05 years (sd 0.63)). The childhood time periods were based on four assessments each, while the adolescent periods were each based on three assessments. Middle and late childhood were used to determine early onset, while subsequent adolescent offending careers were based on data from the early, middle and late adolescent time periods. Potential predictors of offending careers were measured in middle childhood. In the early onset sample, about $38 \%$ of the boys were Caucasian and 63\% were African American, compared to $72.1 \%$ in the general population of Pittsburgh (2000 Census report on the Pittsburgh area). During the first time period, about $26 \%$ of the boys were living with both biological parents at home, and about $63 \%$ of the families were on welfare, compared to the $17.1 \%$ children in Pittsburgh that are living below poverty level (2000 Census report on the Pittsburgh area).

\section{Measures}

Information from multiple informants was combined whenever possible. Correlations between the informants had to be above 0.3 to be combined. If one of the informants scored affirmative on an item, the behavior was assumed to be present. This strategy made it possible to: a) measure behaviors occurring in multiple settings, such as home and school, and b) use a 'best estimate' algorithm to establish whether the behavior occurred at all within the assessment period. Per construct, assessment scores were combined into a mean score per time period if the construct consisted of a scale or into a proportion if the construct was dichotomous. Constructs with an alpha consistently below 0.70 were not used in the analyses.
Dependent Variable

Data on delinquency during the first two time periods, middle and late childhood, were used to select the early onset offenders from the youngest cohort of the PYS. Following, their adolescent offending careers were studied in three time periods: early, middle, and late adolescence, based on the boys' Self-Reported Delinquency Scale (SRD; Elliot et al. 1985), Youth Self Report (YSR; Achenbach and Edelbrock 1987), the Antisocial Behavior Scale (Loeber et al. 1989), the caretakers' Child Behavior Check List (CBCL; Achenbach and Edelbrock 1979, 1983, 1987), the teachers' Teacher Report Form (TRF; Edelbrock and Achenbach 1984), and court records. Several items were added to the parent and teacher forms to increase the common-item pool and to gain more information on delinquent behavior. Delinquency was classified according to five levels of severity (Loeber et al. 2008): level 1: minor delinquency at home, such as vandalism or theft $<\$ 5$; level 2: minor delinquency outside the home, such as vandalism $<\$ 100$ or theft $<\$ 5$; level 3: moderate delinquency, such as gang fights, theft $>\$ 5$, fraud or joyriding; level 4: serious delinquency, such as breaking and entering, robbery, and sex offences; and level 5: multiple serious acts. Participants who displayed at least level 2 antisocial behavior in middle and/or late childhood as reported by parent, child and/or teacher were included in the study.

\section{Childhood Predictors}

Because of the large number of constructs, the potential childhood predictors are summarized in Table 1 (more details are available on request). The measures and variables have been described in earlier publications (Loeber et al. 2008, 1998; Stouthamer-Loeber et al. 1993). Only those independent variables were included that predicted serious persistence or distinguished between the combined moderate to serious persisters group and early desister group (Loeber et al. 2008). The independent variables were organized into six domains: child behaviors, child attitudes, school, peer, family, and demographic characteristics. The direction of the scoring of the independent variables linked high scores to a negative, less desirable connotation.

\section{Analyses}

For all analyses, SPSS version 12.0 was used. Analyses were run in four steps. First, we examined the prevalence, desistance and persistence of childhood onset offending. Persistence and desistance were applied to early onset offenders whose offending started in middle and/or late childhood and refer to the extent to which they continued offending during adolescence. Persistent offending was defined as having offended in at least two out of three adolescent time periods. Desistance 
Table 1 Constructs Tested for Their Potential Promotive and/or Risk Effects

\begin{tabular}{|c|c|c|c|}
\hline & Instrument & Informant (No. Items) & Description/Example \\
\hline \multicolumn{4}{|l|}{ Childhood offence characteristics } \\
\hline Diversity of offending & CBCL, SRD, ABS & $\mathrm{C}, \mathrm{P}, \mathrm{T}$ & $\begin{array}{l}\text { Number of different types of offences } \\
\text { reported in the time period. }\end{array}$ \\
\hline Offending frequency & SRD & $\mathrm{C}$ & Mean frequency of offending per half year \\
\hline \multicolumn{4}{|l|}{ Participant substance use } \\
\hline Any substance use & SUS & $\mathrm{C}(4)$ & $\begin{array}{l}\text { Any involvement in smoking, secret drinking, } \\
\text { or substance use }\end{array}$ \\
\hline \multicolumn{4}{|l|}{ Participant psychopathology disruptive } \\
\hline Attention-deficit hyperactivity & DISC-P & $\mathrm{P}(28)$ & DSM-III-R ADHD symptom score \\
\hline Oppositional behavior & DISC-P & $\mathrm{P}(13)$ & DSM-III-R ODD symptom score \\
\hline \multicolumn{4}{|l|}{ Other disruptive problems } \\
\hline Physical aggression & CBCL & $\mathrm{P}(7), \mathrm{T}(5)$ & \\
\hline Psychopathic features & CBCL & $\mathrm{P}(32), \mathrm{T}(32)$ & $\begin{array}{l}\text { childhood psychopathic features without } \\
\text { delinquent acts }{ }^{a b}\end{array}$ \\
\hline Truancy & $\mathrm{SRD}, \mathrm{CBCL}$ & C (2),P (1),T (1) & \\
\hline Running away & $\mathrm{SRD}, \mathrm{CBCL}$ & $\mathrm{C}(2), \mathrm{P}(1), \mathrm{T}(1)$ & \\
\hline Serious injuries & FHQ & $\mathrm{P}(1)$ & Frequency of sustained serious injuries \\
\hline \multicolumn{4}{|l|}{ Depression and anxiety } \\
\hline Depressed mood & RMF & $\mathrm{C}(13)$ & DSM-III-R major depression criteria \\
\hline Shy/withdrawn & CBCL & C (7), P (7), T (7) & Likes to be alone, does not talk \\
\hline Anxiety & CBCL & C (7), P (7), T (8) & Clingy, nervous, tense \\
\hline \multicolumn{4}{|l|}{ Participant competence } \\
\hline Attitude to delinquency & SRD & $\mathrm{C}(11)$ & Acceptability of delinquent acts \\
\hline Attitude to substance use & ATDBS & $\mathrm{C}(5)$ & Acceptability of illicit drug use \\
\hline Perception of likelihood of getting caught & LBC & $\mathrm{C}(10)$ & Likelihood to be caught by the police \\
\hline Perception of problem behavior & PABS & $\mathrm{C}(15)$ & Acceptability of problem behavior e.g., fighting \\
\hline \multicolumn{4}{|l|}{ Physical development } \\
\hline Prenatal problems & PBD & $\mathrm{P}(1)$ & Medical problems during pregnancy \\
\hline Perinatal problems & PBD & $\mathrm{P}(1)$ & Medical problems during birth \\
\hline Mother smoking during pregnancy & PBD & $\mathrm{P}(1)$ & Has mother smoked \\
\hline Mother drinking during pregnancy & PBD & $\mathrm{P}(1)$ & Has mother used alcohol \\
\hline \multicolumn{4}{|l|}{ Peer behavior } \\
\hline Peer delinquency & SRD & $\mathrm{C}(9)$ & Participation in delinquent acts \\
\hline Relationship with siblings & Demographic & $\mathrm{C}(1), \mathrm{P}(1)$ & With siblings living in the same home \\
\hline Relationship with peers & CBCL & $\mathrm{C}(1), \mathrm{P}(1), \mathrm{T}(1)$ & How well he got along with peers \\
\hline \multicolumn{4}{|l|}{ Family functioning } \\
\hline Boy involvement & & $\mathrm{C}, \mathrm{P}$ & Boys involvement in family activities \\
\hline Persistence of discipline & Discipline & $\mathrm{P}(4)$ & \\
\hline Physical punishment & Discipline & $\mathrm{P}(1), \mathrm{C}(1)$ & Hit / slap / spank for misbehavior \\
\hline Supervision & SI & $\mathrm{C}(4), \mathrm{P}(4)$ & Knowledge of boy's activities \\
\hline Positive parenting & PPS & $\mathrm{P}(9), \mathrm{C}(7)$ & Giving rewards \\
\hline \multicolumn{4}{|l|}{ Parent } \\
\hline Behavioral problems father & FHQ & $\mathrm{P}(1)$ & $\begin{array}{l}\text { Has biological father ever sought help for } \\
\text { behavioral problems? }\end{array}$ \\
\hline Biological parent police contact & & & Arrested or detained by the police \\
\hline Parental stress & & $\mathrm{P}(14)$ & Stress and ability to handle problems \\
\hline Caretaker antisocial attitude & PPB & $\mathrm{P}(18)$ & Opinions on son fighting, skipping school \\
\hline
\end{tabular}


Table 1 (continued)

Instrument Informant (No. Items) Description/Example

\begin{tabular}{|c|c|c|c|}
\hline \multicolumn{4}{|l|}{ School } \\
\hline Academic achievement & CBCL & $\mathrm{C}(7), \mathrm{P}(7), \mathrm{T}(7)$ & Performance in academic subjects \\
\hline Attitude to school & Resources & $\mathrm{C}(7)$ & E.g.: "Ïs homework a waste of time?" \\
\hline Repeated grade & CBCL & $\mathrm{T}(1)$ & Boy too old for grade \\
\hline \multicolumn{4}{|l|}{ Neighborhood } \\
\hline Neighborhood impression & Your Neigh. & $\mathrm{P}(17)$ & Unemployment, crime, vandalism \\
\hline \multicolumn{4}{|l|}{ Demographics } \\
\hline House size & Demographic & $\mathrm{P}(1)$ & Number of rooms in the house \\
\hline Housing quality & HQA & I & Assessment of housing quality \\
\hline Number of biological parents in home & demographic & $\mathrm{P}(1)$ & Count of biological parents in the home \\
\hline Number of children in home & demographic & $\mathrm{P}(1)$ & Count of number of children \\
\hline Race & demographic & $\mathrm{P}(1)$ & African American/Caucasian \\
\hline Age mother at first birth & demographic & $\mathrm{P}(1)$ & Age of mother at the birth of her first child \\
\hline Family SES & demographic & $\mathrm{P}$ & Calculated socio-economic scores \\
\hline Welfare & demographic & $\mathrm{P}(1)$ & $\begin{array}{l}\text { Has one of the family members received } \\
\text { financial support from the state }\end{array}$ \\
\hline
\end{tabular}

Instruments: ATDBS, Attitude Toward Delinquent Behavior Scale; CBCL, Child Behavior Child Checklist, Parent Version (Achenbach and Edelbrock 1979, 1983); Teacher Report Form (Edelbrock and Achenbach 1984); Youth Self-Report Version (Achenbach and Edelbrock 1987); DISC-P, Diagnostic Interview Schedule for Children-Parent version (for DSM-III-R diagnoses; Costello et al. 1985); LBC, Likelihood of Getting Caught Scale; PABS, Perception of Antisocial Behavior Scale; PBD, Problems Birth \& Development questionnaire ; PPB, Perception of Problem Behavior Questionnaire; PPS, Positive Parenting Scale; RMF, Recent Mood and Feelings Questionnaire (Angold et al. 1996; Costello and Angold 1988); SI, Supervision and Involvement Scale; SRD. Self-Reported Delinquency Scale (Elliot et al. 1985; Loeber et al. 1998); SUS Substance Use Scale (Elliot et al. 1985)

${ }^{a}$ Childhood psychopathic features without delinquent acts, developed by Lynam (1997)

was defined as not having shown any offending behavior in either middle or late adolescence. All boys who did not meet the definition criteria of either persistence or desistance were regarded as intermittent offenders. Level of severity was defined by the most serious offence displayed during adolescence. Based on these results, subgroups of serious persisters, moderately serious persisters, desisters and intermittent offenders were formed. Two groups of offenders were excluded from further analyses, the intermittent offenders and the persistent offenders who had not shown any offending behavior in either late childhood or early adolescence.

Second, for the analysis of potential risk and promotive effects, the independent variables were trichotomized as closely as possible at the 25 th and 75 th percentiles to create potentially promotive, neutral, and risk categories. These cutoffs were based on earlier work by Stouthamer-Loeber and colleagues (Stouthamer-Loeber et al. 1993, 2002; Loeber et al. 1998). Similar cut-off scores were used to enhance comparability and compensate for skewed distributions. In addition, the trichotomization of the variables allowed for examination of both their risk and promotive relationships with persistence of adolescent delinquency in $2 \times 2$ tables. Which variables acted as risk variables was established by comparing individuals in the risk range (highest $25 \%$ ) to individuals in the neutral range (middle 50\%). To establish promotive effects, individuals in the promotive range (lowest $25 \%$ ) were compared to those in the neutral range (middle $50 \%$ ). Some variables could only be used dichotomously, for example having a diagnosis or substance use. In that case the variable was regarded as a risk variable. Logistic regression on all these $2 \times 2$ tables was used to determine significance and establish odds ratios. In analyzing the predictors of desistance, we faced problems of modest statistical power because of low cell sizes for some outcomes. For this reason, we report on factors that significantly discriminated at a $p<$ 0.10 level. Because of the large numbers of comparisons, we established whether findings could have been produced by chance alone before moving to the next step of the analyses. To be conservative, we required a minimum p-value of 0.10 (e.g., if less than 10 out of 100 tests were significant, then we did not include that whole set of tests). In all comparisons, the number of predictors measured in middle and late childhood was higher than our pre-established p-value of 0.10 . Therefore, all sets of tests could be run.

Third, the variables identified in the univariate analyses were entered into multiple hierarchical logistic regression analyses comparing between the serious persistent group, the moderately serious persistent and the desistant group. As this paper focuses on desistance and moderately serious versus serious offending, childhood promotive effects were entered first, followed by risk 
effects. A chi-square test of the difference between the two loglikelihood ratios determined whether the introduction of the next block of variables improved the prediction model. Promotive and risk factors were entered as binary variables contrasting the highest or lowest $25 \%$ to the other $75 \%$. All correlates were tested for multicollinearity, which proved not to be a problem. If the number of significant findings in the bivariate analysis was above $10 \%$ of the subsample size, the maximum number of variables that can be reliably entered into a regression analysis, variables with the lowest odds ratios were excluded until the $10 \%$ maximum was reached.

\section{Results}

\section{Adolescent Re-offending Careers}

The first question concerned the prevalence of serious persistent, moderately serious persistent and desistant offending during adolescence in a sample of childhood onset offenders. Overall, $57.7 \%$ of the children in the youngest cohort of the Pittsburgh Youth Study committed one or more offences of at least minor seriousness (level 2) prior to age twelve. As Tables 2 and 3 show, most children who started offending prior to age twelve $(68.3 \%)$ persisted in moderate to serious offending during adolescence as defined by offending in at least two out of three time periods. Nearly half of the persistent offender group (44.8\%) offended seriously during adolescence (peak level of 4 or 5), and are therefore hereafter called serious persisters. The other half (55.2\%) persisted offending at a minor (level 2) to moderate (level 3) peak level of severity. Since the vast majority of these less serious persisters offended at a moderate peak level, they are hereafter called moderately serious persisters. Furthermore, about a fifth of the sample $(20.3 \%)$ desisted offending as defined by absence of any level 2 to 5 offending from early adolescence on (ages 14-19), and are hereafter called desisters. Finally, $11.3 \%$ of the sample re-offended intermittently in adolescence. Intermittent offenders showed considerable variation in offending seriousness and are therefore likely to form a heterogeneous group of offenders. Because of this heterogeneity and the small sample size $(n=35)$, the intermittent group was excluded from further analyses.

\section{Prediction of Early Onset Adolescent Offending Careers}

The second question concerned the prospective discrimination between serious persistent, moderately serious persistent, and desistant offenders. Odds ratios of risk factors are presented in such a way that they are above one if higher percentages were found in the more serious group. To improve readability, promotive factors were transformed so that odds ratios above one represent a higher likelihood of the characteristics in the less serious group. Results will be provided per between group comparison.

\section{Serious Persisters Versus Moderately Serious Persisters}

In middle childhood, $15.2 \%$ of the factors (two promotive and 10 risk) distinguished between boys who persisted in moderately serious and boys who persisted in serious offending, which is better than chance (Table 4). On the promotive side, more of the moderately serious persisters compared to the serious persisters had not experienced perinatal problems $(\mathrm{OR}=1.8)$, and had parents who supervised their sons well $(\mathrm{OR}=2.0)$. On the risk side, more of the serious persisters compared to the moderately serious persisters showed different types of offences $(\mathrm{OR}=2.0)$, high frequency of offending $(\mathrm{OR}=2.9)$, were truant $(\mathrm{OR}=1.7)$, and running away from home $(\mathrm{OR}=2.5)$, had a poor relationship with peers $(\mathrm{OR}=1.7)$, got along poorly with siblings $(\mathrm{OR}=1.8)$, and had parents who reported high levels of stress $(\mathrm{OR}=2.0)$. In contrast, more of the moderately serious persisters compared to the serious persisters resided in poor quality housing $(\mathrm{OR}=0.59)$, had parents who poorly supervised them $(\mathrm{OR}=0.48)$, and displayed a low perceived likelihood of getting caught $(\mathrm{OR}=0.53)$. In summary, albeit some exceptions, in middle childhood more of the boys who persisted in moderately serious offending had been exposed to promotive factors, while more of the boys who persisted in serious offending had been exposed to risk factors. However, given the rather low odds ratios, the between group differences were only moderate.

Next, the significant predictors were entered into a hierarchical regression model (Table 5). ${ }^{1}$ One of the promotive and four of the risk factors independently differentiated between moderately serious and serious persistent offenders. More of the boys who grew up to become moderately serious persisters had experienced no birth complications $(\mathrm{POR}=2.5)$, perceived a low likelihood of getting caught $(\mathrm{POR}=0.31)$, and lived in poor quality housing $(\mathrm{POR}=0.43)$. In contrast, more of the serious persistent compared to the moderately serious persisent offenders in adolescence showed a high frequency of offending during middle childhood $(\mathrm{POR}=3.8)$, and had parents reporting high stress $(\mathrm{POR}=2.1)$. In summary, while individual deviancy and parent problems predicted serious persistence as compared to moderately serious persistence in offending, a risky attitude and social disadvantage predicted moderately serious as compared to serious persistence.

\footnotetext{
${ }^{1}$ Because the supervision showed a curve-linear relation, the variable was entered as a contrast between the average score and the two extreme scores along with the significant risk factors.
} 
Table 2 Prevalence Adolescent Offending Per Age Block

\begin{tabular}{|c|c|c|c|c|c|}
\hline & \multicolumn{5}{|c|}{ Prevalence of adolescent offending } \\
\hline & $\mathrm{n}$ & Early $12-14$ years & Middle $15-17$ years & Late $18-19$ years & Proportion of sample $\%$ \\
\hline \multirow[t]{4}{*}{ Persisters $(n=212)$} & 84 & $\mathrm{X}$ & $\mathrm{X}$ & $\mathrm{X}$ & \multirow[t]{4}{*}{68.4} \\
\hline & $6^{\mathrm{a}}$ & - & $\mathrm{X}$ & $\mathrm{X}$ & \\
\hline & 14 & $\mathrm{X}$ & - & $X$ & \\
\hline & 108 & $\mathrm{X}$ & $X$ & - & \\
\hline \multirow[t]{2}{*}{ Desisters $(n=63)$} & 29 & - & - & - & \multirow[t]{2}{*}{20.3} \\
\hline & $34^{\mathrm{b}}$ & $\mathrm{X}$ & - & - & \\
\hline \multirow[t]{3}{*}{ Intermittent $(n=35)$} & 25 & - & $X$ & - & \multirow[t]{3}{*}{11.3} \\
\hline & 7 & - & - & $X$ & \\
\hline & $3^{\mathrm{a}}$ & - & $\mathrm{X}$ & $\mathrm{X}$ & \\
\hline
\end{tabular}

23 boys were left out of the classification because of too much missing data

${ }^{a}$ Boys who did not offend in both late childhood and early adolescence were not classified as persisters but as intermittent offenders

${ }^{\mathrm{b}} \mathrm{Six}$ of these children had offended in middle childhood and early adolescence and not in late childhood. One could argue these children are in fact intermittent offenders. However, the fact that they did not show offending behavior in the following two adolescent age blocks made us decide to regard them as desisters

\section{Serious Persisters Versus Desisters}

Table 4 shows that in middle childhood, $29.1 \%$ of the factors (eight promotive and 15 risk) distinguished desisters from serious persisters in offending, which was better than chance. In middle childhood, more of the desisters as compared to the serious persisters showed a low frequency of offending $(\mathrm{OR}=1.9)$, low $\mathrm{ADHD}$ symptoms $(\mathrm{OR}=2.4)$, and a negative attitude to delinquency $(\mathrm{OR}=2.2)$. Furthermore, more of the desisters were involved in family activities $(\mathrm{OR}=2.7)$, lived with both parents $(\mathrm{OR}=1.9)$, in small families $(\mathrm{OR}=2.1)$, and in good quality housing $(\mathrm{OR}=2.3)$. In contrast, more of the serious persisters experienced little physical punishment $(\mathrm{OR}=0.47)$. On the risk side, a larger proportion of serious persisters, compared to desisters, showed different offence types $(\mathrm{OR}=2.6)$, high offence frequency $(\mathrm{OR}=2.3)$, physical aggression $(\mathrm{OR}=2.1)$, and psychopathic features $(\mathrm{OR}=2.1)$. Furthermore, more of the serious persisters as compared to the desisters were truant $(\mathrm{OR}=3.5)$, running away $(\mathrm{OR}=3.4)$,

Table 3 Peak Levels of Offending Severity in Adolescence

\begin{tabular}{|c|c|c|c|}
\hline \multirow[t]{2}{*}{$\%$} & Persisters & Desisters $^{\mathrm{a}}$ & Intermittent \\
\hline & $n=212$ & $n=63$ & $n=35$ \\
\hline Minor serious offending & 13.2 & 36.5 & 40.0 \\
\hline $\begin{array}{l}\text { Moderately serious } \\
\text { offending }\end{array}$ & 42.0 & 15.9 & 48.6 \\
\hline Serious offending & 44.8 & 1.6 & 11.4 \\
\hline
\end{tabular}

sustained serious injuries $(\mathrm{OR}=4.8)$, were depressed $(\mathrm{OR}=$ $2.0)$, had highly stressed parents $(\mathrm{OR}=2.5)$, came from large families $(\mathrm{OR}=2.1)$, were on welfare $(\mathrm{OR}=2.8)$, and had young mothers $(\mathrm{OR}=2.2)$. In contrast, desisters as compared to serious persisters more often perceived the likelihood of getting caught to be low $(\mathrm{OR}=0.46)$, and more often had experienced two or more prenatal problems $(0.50)$. In summary, several individual factors, in particular those indicative of deviancy, and family factors distinguished between serious persistent offenders and desistant offenders. However, we found some exceptions to desisters being exposed to fewer risk factors and more promotive factors than persisters in offending.

When the significant univariate findings were entered in a logistic regression (Table 5), two promotive and four risk factors prospectively distinguished between serious persisters in offending and desisters. More of the desisters were involved with family activities ( $\mathrm{POR}=4.3$ ), lived in small families $(\mathrm{POR}=3.5)$, perceived a low likelihood of getting caught $(\mathrm{POR}=0.28)$, and had experienced two or more prenatal problems $(\mathrm{POR}=0.41)$. In contrast, more of the serious persisters were truant $(\mathrm{POR}=3.4)$, and displayed physical aggression $(\mathrm{POR}=3.6)$. In summary, family involvement and, surprisingly, a risky attitude and prenatal problems predicted desistance as compared to serious persistence in offending, while individual deviancy in middle childhood predicted serious persistence in offending as compared to desistance in adolescence.

\section{Moderately Serious Persisters Versus Desisters}

In middle childhood, $13.9 \%$ of the factors (seven promotive and four risk), differentiated between desisters and moder- 
Table 4 Predictors in Middle Childhood Discriminating Between Different Offence Groups

\begin{tabular}{|c|c|c|c|c|c|c|}
\hline & \multirow[b]{2}{*}{$\begin{array}{l}\text { Serious persisters } \\
(n=95) \%\end{array}$} & \multirow[b]{2}{*}{$\begin{array}{l}\text { Moderate } \\
\text { persisters } \\
(n=117) \%\end{array}$} & \multirow[b]{2}{*}{$\begin{array}{l}\text { Desisters } \\
(n=63) \%\end{array}$} & \multicolumn{3}{|c|}{ Group comparisons (odds ratio $(90 \% \mathrm{CI})$ ) } \\
\hline & & & & $\begin{array}{l}\text { Serious persisters } \\
\text { vs moderate } \\
\text { persisters }\end{array}$ & $\begin{array}{l}\text { Serious } \\
\text { persisters vs } \\
\text { desisters }\end{array}$ & $\begin{array}{l}\text { Moderate } \\
\text { persisters vs } \\
\text { desisters }\end{array}$ \\
\hline \multicolumn{7}{|l|}{ Childhood offence characteristics } \\
\hline High offending frequency & 42.1 & 20.5 & 22.2 & $2.9(1.6-5.1)^{* * *}$ & $2.3(1.1-4.5)^{* *}$ & \\
\hline Low offending frequency & 27.4 & 36.8 & 41.3 & & $1.9(1.1-3.3)^{*}$ & \\
\hline Diversity in offending & 63.2 & 46.2 & 39.7 & $2.0(1.3-3.2)^{* *}$ & $2.6(1.5-4.5)^{* * *}$ & \\
\hline \multicolumn{7}{|l|}{ Participant psychopathology disruptive } \\
\hline Low ADHD & 11.1 & 12.6 & 21.3 & & $2.4(1.1-5.2)^{*}$ & \\
\hline \multicolumn{7}{|l|}{ Other disruptive problems } \\
\hline Physical aggression & 42.1 & 35.0 & 25.4 & & $2.1(1.2-3.8)^{* *}$ & \\
\hline High psychopathic features & 42.1 & 33.3 & 27.0 & & $2.1(1.1-3.9)^{* *}$ & \\
\hline Truancy & 45.3 & 32.5 & 19.0 & $1.7(1.1-2.7)^{*}$ & $3.5(1.9-6.6)^{* * *}$ & $2.0(1.1-3.8)^{*}$ \\
\hline Running away & 18.9 & 8.5 & 6.3 & $2.5(1.3-5.0)^{* *}$ & $3.4(1.3-8.9)^{* *}$ & \\
\hline Serious injuries & 19.8 & 20.7 & 4.9 & & $4.8(1.6-13.8)^{* *}$ & $5.1(1.8-14.3)^{* *}$ \\
\hline \multicolumn{7}{|l|}{ Depression and anxiety } \\
\hline High depressed mood & 33.7 & 28.2 & 19.0 & & $2.0(1.1-3.9)^{*}$ & \\
\hline \multicolumn{7}{|l|}{ Participant competence } \\
\hline Negative attitude to delinquency & 16.8 & 23.9 & 30.2 & & $2.2(1.1-4.4)^{* *}$ & \\
\hline Perception of low likelihood of getting caught & 21.1 & 31.9 & 35.0 & $0.53(0.30-0.92)^{*}$ & $0.46(0.24-0.89)^{*}$ & \\
\hline \multicolumn{7}{|l|}{ Physical development } \\
\hline Two prenatal problems & 29.3 & 40.0 & 43.3 & & $0.50(0.26-0.98)^{*}$ & \\
\hline Two perinatal problems & 28.0 & 15.5 & 23.3 & & & \\
\hline No perinatal problems & 39.0 & 57.3 & 35.0 & $1.8(1.0-3.3)^{*}$ & & $0.53(0.28-1.0)^{*}$ \\
\hline \multicolumn{7}{|l|}{ Peer behavior } \\
\hline High peer delinquency & 40.0 & 29.1 & 17.5 & & $2.7(1.4-5.3)^{* *}$ & \\
\hline Gets along poorly with siblings & 28.1 & 20.0 & 25.9 & $1.8(1.0-3.3)^{*}$ & & \\
\hline Gets along well with siblings & 27.0 & 21.9 & 33.3 & & & $2.2(1.1-4.2)^{*}$ \\
\hline Poor relationship with peers & 38.9 & 27.4 & 27.0 & $1.8(1.1-2.9)^{*}$ & & \\
\hline Good relationship with peers & 13.7 & 14.5 & 27.0 & & & $2.3(1.2-4.6)^{* *}$ \\
\hline \multicolumn{7}{|l|}{ Family functioning } \\
\hline High boy Involvement & 18.9 & 20.5 & 36.5 & & $2.7(1.4-5.2)^{* *}$ & $2.4(1.3-4.4)^{* *}$ \\
\hline Low physical punishment & 26.3 & 23.1 & 14.3 & & $0.47(0.23-0.98)^{*}$ & $0.48(0.23-0.98)^{*}$ \\
\hline Poor supervision & 25.3 & 36.8 & 28.6 & $0.48(0.28-0.81)^{* *}$ & & \\
\hline Good supervision & 15.8 & 22.2 & 20.6 & $2.0(1.2-3.4)^{*}$ & & \\
\hline \multicolumn{7}{|l|}{ Parent } \\
\hline High parental stress & 35.8 & 23.1 & 15.9 & $2.0(1.2-3.4)^{* *}$ & $2.5(1.2-5.1)^{* *}$ & \\
\hline Low parental stress & 15.8 & 14.5 & 30.2 & & & $2.4(1.3-4.6)^{* *}$ \\
\hline \multicolumn{7}{|l|}{ Demographics } \\
\hline Poor housing quality & 26.6 & 38.8 & 19.0 & $0.59(0.34-0.97)^{*}$ & & $2.0(1.0-3.9)^{*}$ \\
\hline Good housing quality & 18.1 & 14.7 & 34.9 & & $2.3(1.2-4.5)^{* *}$ & $2.4(1.3-4.6)^{* *}$ \\
\hline Both biological parents at home & 19.1 & 24.8 & 33.3 & & $1.9(1.1-3.8)^{*}$ & \\
\hline$>2$ children at home & 35.8 & 28.2 & 19.0 & & $2.1(1.0-4.1)^{*}$ & \\
\hline Few children at home & 9.5 & 13.7 & 19.0 & & $2.2(1.1-4.9)^{*}$ & \\
\hline Young mother & 34.9 & 31.5 & 18.3 & & $2.2(1.1-4.6)^{*}$ & \\
\hline Welfare & 72.3 & 61.7 & 48.4 & & $2.8(1.6-4.9)^{* * *}$ & $1.7(1.0-2.9)^{*}$ \\
\hline Number of related characteristics & & & & 12 & 23 & 11 \\
\hline
\end{tabular}

Due to rounding error, some of the CI include 1.0 at the extreme of the interval.

The following factors did not discriminate between any of the offence groups: Serious offending, Any substance use, High ADHD, High ODD, Low ODD, Low Psychopathic features, Less depressed mood, Highly shy/withdrawn, Less shy/withdrawn, Highly anxious, Less anxious, Positive attitude to delinquency, Negative attitude to substance use, Positive attitude to substance use, High likelihood of getting caught, Approving problem behavior, Disapproving problem behavior, No prenatal problems, Mother smoking during pregnancy, Mother drinking during pregnancy, Low peer delinquency, Low boy involvement, Low persistence of discipline, High persistence of discipline, High physical punishment, Low positive parenting, High positive parenting, Behavioral problems father, Biological parent police contact, Caretaker antisocial attitude, Caretaker prosocial attitude, Low academic achievement, High academic achievement, Negative attitude to school, Positive attitude to school, Repeated grade, Negative neighborhood impression, Positive neighborhood impression, Small house size, Large house size, Race black, Age mother at first birth $>22$, Low family SES, and High family SES

$* \mathrm{p}<0.1, * * \mathrm{p}<0.05, * * * \mathrm{p}<0.01$ 
Table 5 Middle Childhood Multivariate Prediction Models of Adolescent Offending Persistence and Seriousness Combining Risk and Promotive Factors

\begin{tabular}{|c|c|c|c|c|}
\hline & $\mathrm{B}(\mathrm{SE})$ & Wald & $\mathrm{p}$ & Odds $(95 \% \mathrm{CI})$ \\
\hline \multicolumn{5}{|l|}{ Serious persisters / moderate persisters } \\
\hline \multicolumn{5}{|l|}{ Promotive } \\
\hline No perinatal problems & $0.900(0.343)$ & 6.893 & 0.009 & $2.5(1.3-4.6)$ \\
\hline \multicolumn{5}{|l|}{ Risk } \\
\hline High frequency of offending & $1.331(0.392)$ & 11.510 & 0.001 & $3.8(1.8-8.2)$ \\
\hline Low estimated likelihood of getting caught & $-1.167(0.406)$ & 8.283 & 0.004 & $0.31(0.14-0.69)$ \\
\hline High parental stress & $0.752(0.382)$ & 3.869 & 0.049 & $2.1(1.0-4.5)$ \\
\hline Poor housing quality & $-0.840(0.373)$ & 5.701 & 0.024 & $0.43(0.21-0.90)$ \\
\hline \multicolumn{5}{|c|}{ Overall model: $\chi^{2} 29.389(5), p 0.000$, Nagelkerke $R^{2} 0.209$} \\
\hline \multicolumn{5}{|l|}{ Serious persisters / desisters } \\
\hline \multicolumn{5}{|l|}{ Promotive } \\
\hline High involvement in family activities & $1.460(0.458)$ & 10.143 & 0.001 & $4.3(1.8-10.6)$ \\
\hline Few children in the home & $1.263(0.640)$ & 3.890 & 0.049 & $3.5(1.0-12.4)$ \\
\hline \multicolumn{5}{|l|}{ Risk } \\
\hline Truant & $1.216(0.506)$ & 5.765 & 0.016 & $3.4(1.3-9.1)$ \\
\hline Low likelihood getting caught & $-1.266(0.485)$ & 6.816 & 0.009 & $0.28(0.11-0.73)$ \\
\hline High physical aggression & $1.279(0.513)$ & 6.230 & 0.013 & $3.6(1.3-9.8)$ \\
\hline Two or more prenatal problems & $-0.902(0.435)$ & 3.771 & 0.052 & $0.41(0.17-0.95)$ \\
\hline \multicolumn{5}{|c|}{ Overall model: $\chi^{2} 36.910(6), p 0.000$, Nagelkerke $R^{2} 0.323$} \\
\hline \multicolumn{5}{|l|}{ Moderate persisters / desisters } \\
\hline \multicolumn{5}{|l|}{ Promotive } \\
\hline Good relationship with peers & $1.227(0.482)$ & 6.471 & 0.011 & $3.4(1.3-8.8)$ \\
\hline Low physical punishment & $-1.036(0.528)$ & 3.847 & 0.050 & $0.36(0.13-1.00)$ \\
\hline High involvement of boy in family Activities & $1.077(0.425)$ & 6.407 & 0.011 & $2.9(1.3-6.8)$ \\
\hline No perinatal problems & $-1.223(.388)$ & 9.949 & 0.002 & $0.29(0.14-0.63)$ \\
\hline \multicolumn{5}{|l|}{ Risk } \\
\hline Serious injuries & $1.630(0.684)$ & 5.677 & 0.017 & $5.1(1.3-19.5)$ \\
\hline Poor housing quality & $0.9359(0.422)$ & 4.914 & 0.027 & $2.5(1.1-5.8)$ \\
\hline
\end{tabular}

ately serious persisters in offending, which is just above the $10 \%$ chance limit (Table 4 ). On the promotive side, more of the desisters as compared to the moderately serious persisters had good relationships with peers $(\mathrm{OR}=2.3)$, got along well with siblings $(\mathrm{OR}=2.2)$, and were highly involved in family activities $(\mathrm{OR}=2.4)$. In addition, more of the desisters were living in a good quality house $(\mathrm{OR}=2.4)$, and more of their parents experienced little stress $(\mathrm{OR}=$ 2.4). In contrast, low physical punishment $(\mathrm{OR}=0.48)$ and having experienced no perinatal problems $(\mathrm{OR}=0.53)$ was more common among moderately serious persisters as compared to desisters in offending. On the risk side, more moderately serious persisters compared to desisters were truant $(\mathrm{OR}=2.0)$, and sustained serious injuries $(\mathrm{OR}=5.1)$. The families of moderately serious persisters more often resided in poor quality housing $(\mathrm{OR}=2.0)$, and more often received welfare $(\mathrm{OR}=1.7)$. The results indicate some potentially malleable promotive factors were related to a better outcome such as relationships with peers and siblings. On the other hand, some individual and sociodemographic risk factors in addition to some factors that are generally regarded as promotive of a good outcome were associated with moderately serious persistence as compared to desistance in offending.

Next, significant predictors were entered into a regression analysis (Table 5). Four promotive and two risk factors entered the model. In middle childhood, more of the desisters as compared to the moderately serious persisters in offending had a good relationship with peers $(\mathrm{POR}=3.4)$ and were involved in family activities $(\mathrm{POR}=2.9)$. In contrast, being exposed to no birth complications $(\mathrm{POR}=$ $0.29)$ and low physical punishment $(\mathrm{POR}=0.36)$ was more common among moderately serious persisters as compared to desisters. On the risk side, more of the moderately 
serious persistent as compared to the desistant offenders sustained serious injuries $(\mathrm{POR}=5.1)$ and lived in poor quality housing $(\mathrm{POR}=2.5)$. In summary, compared to moderately serious persistence in offending early onset desistance is predicted by positive social bonds, while moderately serious persistence as compared to desistance is predicted by individual deviancy, social disadvantage, and surprisingly by being exposed to no birth complications and low physical punishment.

\section{Discussion}

The overall aim of this study was to explore the impact of childhood risk and promotive factors on desistance in early adolescence and the severity level of persistence in offending in adolescence in a sample of childhood onset offenders. We examined this by comparing early onset serious persistent offenders, moderately serious persistent offenders and desistant offenders. Childhood onset offenders showed considerable variation in the duration and maximum seriousness of their adolescent offending career. About half of the boys in the youngest cohort of the Pittsburgh Study displayed delinquent behavior between ages 7 and 12 years. One third persisted in serious offending, while another third persisted in moderately serious offences. Furthermore, one in five of these early onset offenders desisted from offending during adolescence, a period in which boys tend to become delinquent. Thus, in line with prior research (Loeber et al. 2008; Loeber and Farrington 2001; Chung et al. 2002), early onset offenders are at high risk for re-offending but cannot be regarded as a homogenous group who all will re-offend during adolescence. Moreover, the finding that the persistence of moderately serious offending was as common as the persistence of serious offending stresses the need to not only focus on serious offenders but also study their less serious, although still costly, counterparts. Finally, contrary to theories by Moffitt (1993) and others, early desistance was rather common. Although some of the desisters may actually be regarded as experimenters, others, for instance those who offended into early adolescence, did have a substantial childhood offending career prior to desisting.

Based on the explained variance, both serious persisters and moderately serious persisters could be distinguished well from early onset offenders who desisted in early adolescence, while it proved more difficult to distinguish between moderately serious and serious persisters in offending. More of the serious persisters compared to the moderately serious persisters displayed disruptive behavior early in life, and thus appear to be more advanced on the developmental pathway to a serious outcome when young. Contrary to Moffitt's hypothesis that the presence of internalizing pathology causes childhood onset offenders to show low levels of persistence in adolescence, no association was found between levels of internalising problems such as depression, shyness and anxiety, and moderately serious persistence. Further, although many of the risk and promotive factors did not distinguish between serious persisters and moderately serious persisters, the two groups differed on several constructs in the expected direction in that more of the serious persisters are exposed to risk factors, and fewer are exposed to promotive factors. A few results were different than expected as moderately serious persisters, compared to serious persisters, were characterized by the absence of developmental problems, and the presence of social disadvantage. Odds ratios of found differences were rather low which suggests that moderately serious persisters and serious persisters are not so much exposed to qualitatively different risk and promotive factors but rather that more of the serious persisters than the moderately serious persisters are exposed to risk factors and fewer to promotive factors.

A high level of individual deviancy was also found predictive of serious persistence in offending when compared to desistance, while desisters were more marked by positive family factors such as involvement in family activities and small family size. Given the high proportion of individual deviance, the serious persistent offender group mostly resembles the early onset life course persistent group as described by Moffitt (1993). As childhood disruptive behavior is particularly predictive of serious persistence, genetic influences may be of more influence on serious as compared to moderately serious persistence in offending. However, so far, studies have not focussed on differences in genetic influences among early onset offenders. Regarding the number of risk and promotive factors, more of the serious persisters were exposed to risk factors while more of the desisters were exposed to promotive factors. However, contrary to the expectations, a low perceived likelihood of getting caught and not having endured perinatal problems were found predictive of desistance in stead of serious persistence. Given the odds ratios, serious persisters and desisters are not so much exposed to qualitatively different risk and promotive factors but rather to quantitative differences in the number of children that are exposed to risk factors and promotive factors.

More of the moderately serious persisters as compared to the desisters in offending were marked by a combination of individual deviancy and social disadvantage, while more desisters were marked by pro-social bonds as apparent from high family involvement and good relationships with peers. Surprisingly, more of the desisters as compared to moderately serious persisters were characterized by the absence of birth complications and low physical punishment. Keeping in mind that the proportion of individual deviancy was lower among moderately serious persisters than among serious persisters in offending, while the proportion of social disadvantage was 
higher, the results suggest that the combination between individual deviancy and social disadvantage as proposed in for instance social control theory (e.g. Thornberry and Krohn 2001) is particularly important for less serious persistence. These findings are in line with previous findings by Wikström and Loeber (2000) who reported a higher impact of environmental risk factors on offending in the relative absence of individual problems. Albeit some exceptions, more of the moderately serious persisters were exposed to risk factors while more of the desisters were exposed to promotive factors suggesting a dose-response relationship. However, in both groups, children are to some extent exposed to the risk and promotive factors, and as such differences seem to be quantitative rather than qualitative in nature.

Positive social bonds were predictive of early adolescent desistance as compared to persistence in offending, which is in line with social control theory which hypothesizes social bonds and pro-social potential by age 8 to be of particular relevant to desistance (Thornberry and Krohn 2001). However, contrary to this theory, none of the school related characteristics such as academic achievement and attitude to school differentiated between groups. Pro-social bonds are potentially malleable and could therefore be targeted by early interventions aimed at the family and the child's early social environment. Moreover, several studies have shown interventions aimed at the family and the peer group to be effective in reducing antisocial behavior in children (e.g. Patterson et al. 2004).

In line with more dimensional theories on offending (e.g. Thornberry and Krohn 2001; Sampson and Laub 2005), the findings largely support the notion of a dose-response relationship between risk and promotive factors and persistence versus desistence in offending. Further, in line with these theories, moderately serious persisters tend to show intermediate levels of risk and promotive factors as compared to serious persisters and desisters in offending. The current study shows that a large proportion of the early onset persistent offenders committed only moderately serious offenses. This indicates that persistence and seriousness of offending are two different dimensions of an offending career that both should be taken into account when studying early onset adolescent re-offending careers. Finally, similar to findings by Stouthamer-Loeber et al. (2004), far fewer constructs that have been found predictive of serious and/or persistent offending in the general population (e.g. Stouthamer-Loeber et al. 2002) predicted differences within childhood onset offenders. As a result, factors found predictive of persistent offending in the general population cannot be assumed to predict persistence and desistance in a sample of early onset offenders.

Contrary to expectations, several characteristics were predictive of persistence while they are generally regarded as promotive of desistance and vice versa. Before any firm conclusions can be drawn on these exceptional findings, they need replication in other studies. Furthermore, even if the findings are replicated, it would not imply that one should promote physical punishment or no longer prevent birth complications. First of all, that would be inhumane since these characteristics are still promotive of the general well being of the child. Second, the fact that a normally positive characteristic is a predictor of persistence does not imply causality. For instance, not having experienced any birth complications is unlikely to cause moderately serious persistence. It is more likely that children who persist in moderately serious offending do so because of other risk factors and despite the fact that they did not endure any trauma during birth.

Finally, although some univariate results, such as running away, negative attitudes to delinquency, teen motherhood and welfare were not found independently predictive in a regression model, they may still be of value when screening and intervening with early onset children. First, several factors are important to paint a full picture of the individual and provide insight into potential underlying mechanisms that influence or cause a predictive risk factor. For instance, a significantly higher proportion of parents of serious persisters faced high levels of stress. This stress can be related to the behavior of the child but also to other factors such as financial problems or psychopathology in the parent that require screening before an intervention can be effective. On the other hand, if the stress is related to the behavior of the child, it could increase parents' motivation for seeking treatment. Second, some predictors may be interrelated, and while the strongest one enters the regression model other predictors may be easier to change by means of an intervention. For instance, poor housing quality may be somewhat difficult to change, but stimulating paid work by the parents through a job coach and courses may increase their financial status and allow them to live in a better quality home. In summary, univariate findings may offer important information for effective intervention.

This study has several limitations. First, the current study was exploratory in nature, and in that spirit included a large number of comparisons. As a consequence, our conclusions are somewhat tempered. Second, the study only focuses on boys in a single urban setting. Third, our definition of desistance referred to desistance over at least six years, but may not mean permanent desistance and some relapse could occur in the future. In a similar vein, less serious persisters may become serious persisters in the future. In this study we treated desistance, serious offending and moderate offending as outcome states, rather than processes or patterns over time, an approach suitable for studying promotive and risk factors. Fourth, we defined severity on the basis of the most serious offense rather than also considering the number of offences that were committed. It could be questioned whether frequent moderate offenders are less serious than offenders who offend 
at low frequency but have committed one serious offence. Fifth, we did not distinguish between boys who escalated to serious offending in adolescence and those who were already serious offenders in childhood. In future research it will be important to focus more on intra-individual changes in the frequency and seriousness of offending over time utilizing person-based analytic strategies (Nagin et al. 1995). Sixth, the study initially was not designed to measure promotive factors. Promotive factors were created in retrospect by using the opposite extremes of known risk factors. In the future, other factors such as social skills, positive parenting and positive peer processes may show additional promotive effects. Finally, because of the explorative nature of the current study we were not able to test for specific interactions between risk and promotive factors. Therefore, future research should focus on specific domains that have been found predictive of escalation, maintenance and desistance from juvenile offending careers. Such studies could thereby focus more on the interaction between specific characteristics such as parenting styles and child temperament, or cognitive functioning and psychopathic features. Improving insight into early desistance of children at such high risk of developing into persistent offenders could have great impact on the prevention of future offending. Thereby the focus should be on the identification of potentially malleable factors that could be targeted by early intervention.

Acknowledgements This study was funded by the Office of Juvenile Justice and Delinquency Prevention, United States Department of Justice (OJJDP 2005-JK-FX-0001), the National Institute of Mental Health (MH 50778) and the National Institute on Drug Abuse (DA 411018). In addition, it was supported by travel grants from the "De Drie Lichten" Foundation and the Netherlands Organization for Scientific Research (NWO). Points of view or opinions in this document are those of the authors and do not necessarily represent the official position or policies of the United States Department of Justice, the National Institute of Mental Health, or the National Institute on Drug Abuse.

Open Access This article is distributed under the terms of the Creative Commons Attribution Noncommercial License which permits any noncommercial use, distribution, and reproduction in any medium, provided the original author(s) and source are credited.

\section{References}

Achenbach, T. M., \& Edelbrock, C. S. (1979). The child behavior profile: II. Boys aged $12-16$ and girls aged 6-11 and 12-16. Journal of Consulting and Clinical Psychology, 47, 223-233. doi:10.1037/0022-006X.47.2.223.

Achenbach, T. M., \& Edelbrock, C. S. (1983). Manual for the child behavior checklist and revised child behavior profile. Burlington, VT: University of Vermont, Department of Psychiatry.

Achenbach, T. M., \& Edelbrock, C. S. (1987). Manual for the youth self-report and profile. Burlington, VT: University of Vermont, Department of Psychiatry.

Aguilar, B., Sroufe, L. A., Egeland, B., \& Carlson, E. (2000). Distinguishing the early-onset/persistent and adolescence-onset antisocial behavior types: from birth to 16 years. Development and Psychopathology, 12, 109-132. doi:10.1017/S0954579 400002017.

Akers, R. L. (1998). Social learning and social structure: A general theory of crime and deviance. Boston: Northeastern University Press.

Angold, A., Patrick, K., Burns, B., \& Costello, E. (1996). The child and adolescent impact assessment (CAIA). Durham, NC: Duke University School of Medicine.

Chung, I. J., Hill, K. G., Hawkins, J. D., Gilchrist, L. D., \& Nagin, D. S. (2002). Childhood predictors of offense trajectories. Journal of Research in Crime and Delinquency, 39, 60-90. doi:10.1177/ 002242780203900103.

Costello, E. J., \& Angold, A. (1988). Scales to assess child and adolescent depression - checklists, screens, and nets. Journal of the American Society of Child and Adolescent Psychiatry, 27, 726-737.

Costello, E. J., Edelbrock, C., \& Costello, A. J. (1985). The validity of the NIMH Diagnostic Interview Schedule for Children (DISC): A comparison between pediatric and psychiatric referrals. Journal of Abnormal Child Psychology, 13, 579-595.

Cottle, C. C., Lee, R. J., \& Heilbrun, K. (2001). The prediction of criminal recidivism in juveniles - a meta-analysis. Criminal Justice and Behavior, 28, 367-394. doi:10.1177/0093854801028003005.

Edelbrock, C. S., \& Achenbach, T. M. (1984). The teacher version of the child behavior Profile: I. Boys aged 6-11. Journal of Consulting and Clinical Psychology, 52, 207-217. doi:10.1037/ 0022-006X.52.2.207.

Elliot, D. S., Huizinga, D., \& Ageton, S. S. (1985). Explaining delinquency and drug use. Beverly Hills, CA: Sage.

Farrington, D. P., \& Hawkins, J. D. (1991). Predicting participation, early onset, and later persistence in officially recorded offending. Criminal Behaviour and Mental Health, 1, 1-33.

Fergusson, D. M., \& Horwood, L. J. (2002). Male and female offending trajectories. Development and Psychopathology, 14, 159-177. doi:10.1017/S0954579402001098.

Fergusson, D. M., Lynskey, M. T., \& Horwood, L. J. (1996). Factors associated with continuity and changes in disruptive behavior patterns between childhood and adolescence. Journal of Abnormal Child Psychology, 24, 533-553. doi:10.1007/BF01670099.

Glueck, S., \& Glueck, E. (1943). Criminal careers in retrospect. New York: The Commonwealth Fund.

Gottfredson, M. R., \& Hirschi, T. (1990). A general theory of crime. Stanford, CA: Stanford University Press.

Granic, I., \& Patterson, G. R. (2006). Toward a comprehensive model of antisocial development: a dynamic systems approach. Psychological Review, 113, 101-131. doi:10.1037/0033-295X.113. 1.101 .

Hirschi, T. (1969). Causes of delinquency. Berkeley: University of California Press.

Kazemian, L., \& Farrington, D. P. (2005). Comparing the validity of prospective, retrospective, and official onset for different offending categories. Journal of Quantitative Criminology, 21, 127147. doi:10.1007/s10940-005-2489-0.

Lacourse, E., Nagin, D., Trembaly, R. E., Vitaro, F., \& Claes, M. (2003). Developmental trajectories of boys' delinquent group membership and facilitation of violent behaviors during adolescence. Development and Psychopathology, 15, 183-197. doi:10.1017/S0954579403000105.

Laub, J. H., \& Sampson, R. J. (2001). Understanding desistance from crime. Crime and Justice, 28, 1-69.

Lee, S. S., \& Hinshaw, S. P. (2004). Severity of adolescent delinquency among boys with and without attention deficit hyperactivity disorder: predictions from early antisocial behavior and peer status. Journal of Clinical Child and Adolescent Psychology, 33, 705-716. doi:10.1207/s15374424jccp3304_6. 
Loeber, R., \& Farrington, D. P. (eds). (2001). Child delinquents: Development, intervention and service needs. Thousand Oaks, CA: Sage.

Loeber, R., \& Le Blanc, M. (1990). Toward a developmental criminology. Crime and Justice: A Review of Research, 12, 375-473.

Loeber, R., \& Wikström, P.-O. (2000). Do disadvantaged neighborhoods cause well-adjusted children to become adolescent delinquents? Criminology, 38, 1109-1142. doi:10.1111/j.17459125.2000.tb01416.x.

Loeber, R., Stouthamer-Loeber, M., Van Kammen, W. B., \& Farrington, D. P. (1989). Development of a new measure of self-reported antisocial behaviour for young children: Prevalence and reliability. In M. Klein (ed.), Cross-national research in selfreported crime and delinquency (pp. 203-225). Boston: KluwerNijhoff.

Loeber, R., Wung, P., Keenan, K., Giroux, B., Stouthamer-Loeber, M., Van Kammen, W. B., et al. (1993). Developmental pathways in disruptive child behavior. Development and Psychopathology, 5, 101-132. doi:10.1017/S0954579400004296.

Loeber, R., Stouthamer-Loeber, M., \& Van Kammen, W. B. (1998). Antisocial behavior and mental health problems: Explanatory factors in childhood and adolescence. Mahwah, NJ: Erlbaum.

Loeber, R., Farrington, D. P., Stouthamer-Loeber, M., \& White, H. R. (2008). Violence and serious theft: Risk and promotive factors from childhood to early adulthood. Mahwah, New Jersey: Lawrence Erlbaum.

Lösel, F., \& Bender, D. (2003). Protective factors and resilience. In D. P. Farrington \& J. W. Coid (Eds.), Early prevention of adult antisocial behaviour (pp. 130-204). Cambridge: Cambridge University Press.

Lynam, D. R. (1997). Pursuing the psychopath: Capturing the fledgling psychopath in a nomological net. Journal of Abnormal Child Psychology, 107, 375-389.

Miller-Johnson, S., Coie, J. D., MAumary-Gremaud, A., Lochman, J., \& Terry, R. (1999). Relationship between childhood peer rejection and aggression and adolescent delinquency severity and type among African American youth. Journal of Emotional and Behavioral Disorders, 7, 137-147. doi:10.1177/10634266 9900700302.

Moffitt, T. E. (1993). Adolescence-limited and life-course-persistent antisocial behavior: a developmental taxonomy. Psychological Review, 100, 674-701. doi:10.1037/0033-295X.100.4.674.

Moffitt, T. E., Caspi, A., Harrington, H., \& Milne, B. J. (2002). Males on the life-course-persistent and adolescence-limited antisocial pathways: follow-up at age 26 years. Development and Psychopathology, 14, 179-207. doi:10.1017/S0954579402001104.

Nagin, D., \& Tremblay, R. E. (1999). Trajectories of boys' physical aggression, opposition, and hyperactivity on the path to physically violent and nonviolent juvenile delinquency. Child Development, 70, 1181-1196. doi:10.1111/1467-8624.00086.

Nagin, D., \& Tremblay, R. E. (2001). Parental and early childhood predictors of persistent physical aggression in boys from kindergarten to high school. Archives of General Psychiatry, 58, 269-278. doi:10.1001/archpsyc.58.4.389.

Nagin, D. S., Farrington, D. P., \& Moffitt, T. E. (1995). Life-course trajectories of different types of offenders. Criminology, 33, 111139.

Paternoster, R. (1989). Absolute and restrictive deterrence in a panel of youth - explaining the onset, persistence and desistance, and frequency of delinquent offending. Social Problems, 36, 289309. doi:10.1525/sp.1989.36.3.03a00060.
Patterson, G. R. (1996). Some characteristics of a developmental theory of early-onset delinquency. In M. F. Lenzenweger \& J. J. Haugaard (Eds.), Frontiers of developmental psychopathology. New York: Oxford University Press.

Patterson, G. R., Forgatch, M. S., Yoerger, K. L., \& Stoolmiller, M. (1998). Variables that initiate and maintain an early-onset trajectory for juvenile offending. Development and Psychopathology, 10, 531-547. doi:10.1017/S0954579498001734.

Patterson, G. R., DeGarma, D., \& Forgatch, M. S. (2004). Systematic changes in families following prevention trials. Journal of Abnormal Child Psychology, 32, 621-633. doi:10.1023/B: JACP.0000047211.11826.54.

Pollard, J., Hawkins, J. D., \& Arthur, M. A. (1999). Risk and protection: are both necessary to understand diverse behavioral outcomes in adolescence. Social Work Research, 23, 145-158.

Raine, A., Yaralian, P. S., Reynolds, C., Venables, P. H., \& Mednick, S. A. (2002). Spatial but not verbal cognitive deficits at age 3 years in persistently antisocial individuals. Development and Psychopathology, 14, 25-44. doi:10.1017/S0954579402001025.

Raine, A., Moffit, T. E., Caspi, A., Loeber, R., Stouthamer-Loeber, M., \& Lynam, D. (2005). Neurocognitive Impairments in boys on the life-course persistent antisocial path. Journal of Abnormal Psychology, 114, 38-49. doi:10.1037/0021-843X.114.1.38.

Sampson, R. J., \& Laub, J. H. (1993). Turning points in the life course: why change matters to the study of crime. Criminology, 31, 301-325. doi:10.1111/j.1745-9125.1993.tb01132.x.

Sampson, R. J., \& Laub, J. H. (2005). A life-course view on the development of crime. The Annals of the American Academy of Political and Social Science, 602, 12-45. doi:10.1177/ 0002716205280075.

Stouthamer-Loeber, M., Loeber, R., Farrington, D. P., Zhang, Q., Van Kammen, W. B., \& Maguin, E. (1993). The double edge of protective and risk-factors for delinquency - interrelations and developmental patterns. Development and Psychopathology, 5, 683-701.

Stouthamer-Loeber, M., Loeber, R., Wei, E., Farrington, D. P., \& Wikström, P.-O. H. (2002). Risk and promotive effects in the explanation of persistent serious delinquency in boys. Journal of Consulting and Clinical Psychology, 70, 111-123. doi:10.1037/ 0022-006X.70.1.111.

Stouthamer-Loeber, M., Wei, E., Loeber, R., \& Masten, A. F. (2004). Desistance from persistent serious delinquency in the transition to adulthood. Development and Psychopathology, 16, 897-918. doi:10.1017/S0954579404040064.

Stouthamer-Loeber, M., Loeber, R., Stallings, R., \& Lacourse, E. (2008). Desistance from and Persistence in Offending. In R. Loeber, D. P. Farrington, M. Stouthamer-Loeber \& H. R. White (Eds.), Violence and serious theft: Risk and promotive factors from childhood to early adulthood. Mahwah, New Jersey: Lawrence Erlbaum.

Thornberry, T. P. (2005). Explaining multiple patterns of offending across the life course and across generations. The Annals of the American Academy of Political and Social Science, 602, 156195. doi:10.1177/0002716205280641.

Thornberry, T. P., \& Krohn, M. D. (2001). The development of delinquency: An interactional perspective. In S. O. White (Ed.), Handbook of Youth and Justice. New York: Plenum.

Wikström, P-O., \& Loeber, R. (2000). Do disadvantaged neighborhoods cause well-adjusted children to become adolescent delinquents? A study of male juvenile serious offending, risk and protective factors, and neighborhood context. Criminology, $38,1109-1142$. 